\title{
Iron Deficiency Anemia with Marked Thrombocytosis Complicated by Central Retinal Vein Occlusion
}

\author{
Tadashi NAgAI, Norio KomAtsu*, Yoichi SAKATA*, Yasusada MiURA and Keiya OzAWA
}

\begin{abstract}
We report a case of severe iron deficiency anemia with marked thrombocytosis that was complicated by central retinal vein occlusion. Platelet count was over one million per microliter and an increased number of megakaryocytes was observed in the bone marrow at the time of diagnosis of iron deficiency anemia, features that resemble those of essential thrombocythemia. However, the platelet count rapidly declined with the administration of ferrous fumarate. Accordingly, central retinal vein occlusion was improved and has not recurred. In this case, significant thrombocytosis caused by iron deficiency anemia may have been involved in the development of central retinal vein occlusion.

(Internal Medicine 44: 1090-1092, 2005)
\end{abstract}

Key words: iron deficiency anemia, central retinal vein occlusion, thrombocytosis

\section{Introduction}

Increases in the count and activity level of platelets in patients with iron deficiency anemia have been reported $(1,2)$. It may be difficult to distinguish iron deficiency anemia from hematopoietic tumors such as essential thrombocythemia when significant thrombocytosis is observed. In most cases of iron deficiency anemia, however, the platelet count decreases to the normal level with improvement of anemia (2$4)$.

A disturbance of retinochoroidal circulation can accompany some blood abnormalities, including iron deficiency anemia (5). The disturbance causes various ophthalmic disorders, including retinal vein occlusion and retinal artery occlusion (6-9). It has been speculated that the disturbance of retinochoroidal circulation is caused by formation of thrombosis due to hypoxia-induced injury of angioendothelial cells, deregulation of the coagulation/fibrinolytic system and thrombocytosis in iron deficiency anemia $(5,7)$.

Here, we report a case of iron deficiency anemia with a marked increase in platelet count, which was over $100.0 \times$ $10^{4} / \mu 1$. The patient had the complication of central retinal vein obstruction, which might have been caused by significant thrombocytosis.

For editorial comment, see p 1025.

\section{Case Report}

A 29-year-old woman visited a local hospital in December 1996 because of deterioration of eyesight. She also had a 2week history of general fatigue and shortness of breath. The examination revealed that the deterioration of eyesight was caused by occlusion of a central retinal vein (Fig. 1A). The patient was referred to Jichi Medical School Hospital. Hematological examination showed a significant decrease in hemoglobin concentration $(4.5 \mathrm{~g} / \mathrm{dl})$ and marked decreases in MCV (55 fl) and MCH (16.6 pg). Laboratory examinations disclosed low serum iron concentration $(5 \mu \mathrm{g} / \mathrm{dl})$, high level of UIBC $(535 \mu \mathrm{g} / \mathrm{dl})$ and low level of serum ferritin (4.0 $\mathrm{ng} / \mathrm{ml})$. Based on these findings, the patient was diagnosed as having iron deficiency anemia. At that time, marked thrombocytosis $\left(102.0 \times 10^{4} / \mu \mathrm{l}\right)$ was also observed. A bone marrow aspiration sample showed hypercellularity with an increased number of megakaryocytes, features consistent with those of essential thrombocythemia (Fig. 1B). Chromosomal analysis of bone marrow cells revealed normal karyotype.

Ferrous fumarate was administered for treatment for the iron deficiency anemia. With daily administration of $100 \mathrm{mg}$ ferrous fumarate, the hemoglobin concentration rapidly

From the Divisions of Hematology and *Cell and Molecular Medicine, Jichi Medical School, Tochigi. "Present address: the Department of Hematology, University of Yamanashi, Tamaho, Yamanashi 409-3898

Received for publication March 10, 2005; Accepted for publication June 2, 2005

Reprint requests should be addressed to Dr. Tadashi Nagai, the Division of Hematology, the Department of Medicine, Jichi Medical School, 3311-1 Yakushiji, Minamikawachi-machi, Kawachi-gun, Tochigi 329-0498 


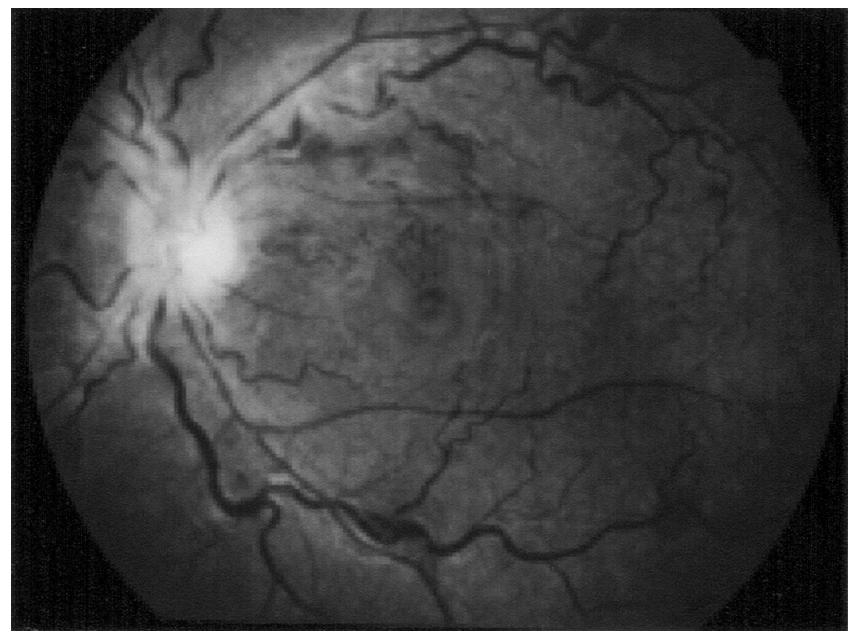

A

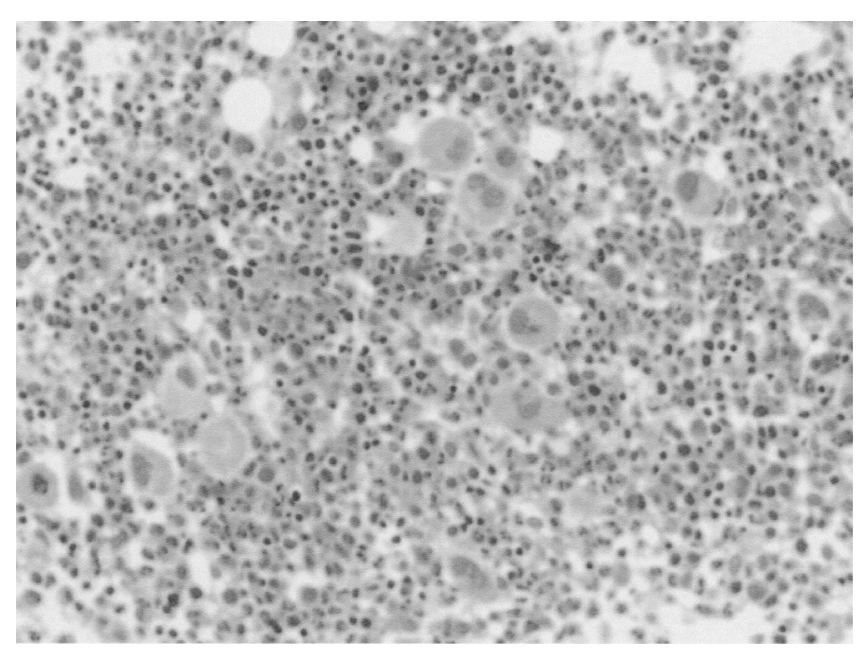

$\mathrm{B}$

Figure 1. (A) Fundus findings at the time of diagnosis of iron deficiency anemia. Retinal hemorrhage, dilatation and narrowing of vessels and macular edema are demonstrated. (B) Histopathological analysis showed bone marrow hyperplasia with a significant increase in megakaryocytes (HE stain, $\times 400)$.

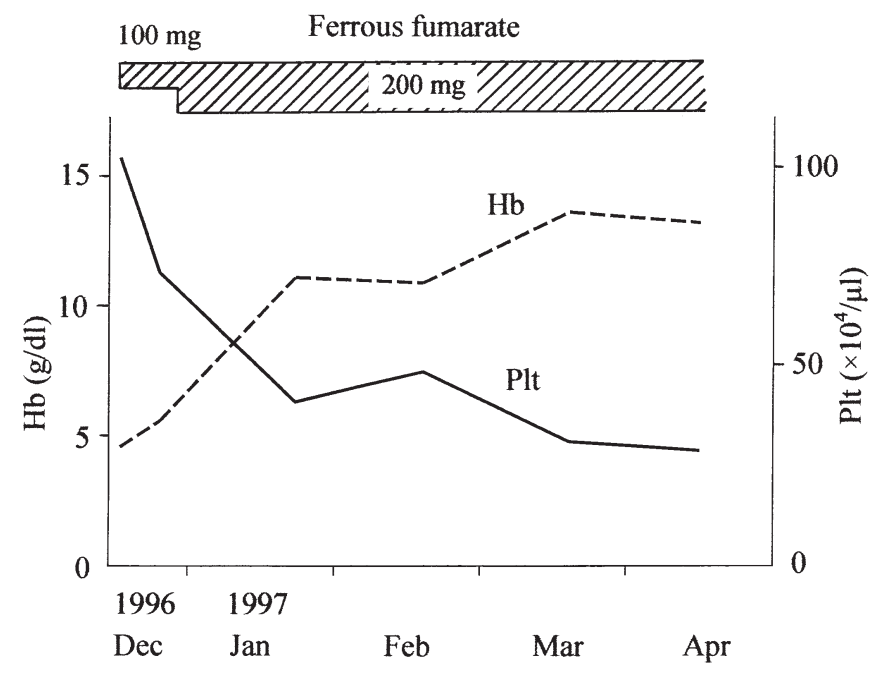

Figure 2. Clinical course. Hemoglobin concentration increased and platelet count simultaneously decreased after administration of ferrous fumarate.

increased and the platelet count simultaneously declined (Fig. 2). During the clinical course, her eyesight gradually improved and occlusion of the central retinal vein has not developed again. Both hemoglobin concentration and platelet count had reached normal ranges three months after the start of treatment. The level of serum ferritin had increased to 50 $\mathrm{ng} / \mathrm{ml}$ in April 1997. We found the existence of myoma uteri, which was thought to be the main cause of iron deficiency anemia, and myomectomy was performed in September 1997.

\section{Discussion}

We describe a case of iron deficiency anemia with significant thrombocytosis that was complicated by central retinal vein occlusion. Thrombocytosis is sometimes observed in cases of iron deficiency anemia, though the mechanisms of increase in platelet count remain unclear. Unlike in myeloproliferative diseases such as essential thrombocythemia, it is unusual for the platelet count to exceed $100.0 \times 10^{4} / \mu 1$ (4). In this case, a marked increase in platelet count $\left(102.0 \times 10^{4} /\right.$ $\mu \mathrm{l})$ was observed when the diagnosis of iron deficiency anemia was made. Although a bone marrow examination suggested that thrombocytosis originated in essential thrombocythemia, platelet count was rapidly reduced to the normal range by ferrous fumarate administration (Fig. 2). To the best of our knowledge, an increase of megakaryocytes in bone marrow of patients with iron deficiency anemia has not been described in previous reports. However, the present clinical course suggested that the marked thrombocytosis observed at the time of diagnosis was associated with iron deficiency anemia.

In iron deficiency anemia, complications due to formation of a thrombus (e.g., cerebral infarction) are occasionally observed $(1,10-12)$. Disturbance of retinochoroidal circulation such as retinal vein occlusion is one such complication observed in patients with this disorder. It has been reported that blood abnormalities, including iron deficiency anemia, are involved in the disturbance of retinochoroidal circulation in many young patients who usually do not have arteriosclerosis (6-9). The mechanisms of iron deficiency anemiainduced disturbance of retinochoroidal circulation remain unclear; however, formation of a thrombus due to hypoxiainduced injury of angioendothelial cells and deregulation of 
the coagulation-fibrinolysis system as well as thrombocytosis may be involved in the development of such ophthalmic disorders $(5,7)$. In fact, patients with iron deficiency anemia who have no thrombocytosis can also be complicated by disturbance of retinochoroidal circulation. In addition, the functions of platelets such as aggregation activity can be altered in patients with iron deficiency anemia (13-16). In the present case, almost normal prothrombin time (12.6 seconds) and activated partial thromboplastin time (26.2 seconds) were demonstrated at the time of diagnosis, suggesting that deregulation of the coagulation-fibrinolysis system was not mainly involved in the disturbance of retinochoroidal circulation. Other iron deficiency anemia-related mechanisms may therefore have been involved in the thrombosis and in the development of central retinal vein occlusion. Particularly, a significant thrombocytosis might have facilitated the development of central retinal vein occlusion in the present patient.

In conclusion, reactive thrombocytosis rarely causes severe thrombus-related complications (1). However, iron deficiency anemia is occasionally complicated by disturbance of retinochoroidal circulation. Since iron deficiency anemiainduced disturbance of retinochoroidal circulation can generally be restored if anemia is improved, it is important to treat a patient promptly for iron deficiency anemia. In the present patient, eyesight was completely restored by administration of ferrous fumarate, and there has been no recurrence of eyesight deterioration.

\section{References}

1) Keung YK, Owen J. Iron deficiency and thrombosis: literature review. Clin Appl Thromb Hemost 10: 387-391, 2004.

2) Gross $S$, Keefer V, Newman AJ. The platelets in iron-deficiency anemia. I. The response to oral and parenteral iron. Pediatrics 34: 315-323, 1964.
3) Cid J, Lozano M. Hemoglobin levels and platelet counts after iron therapy in iron deficiency anemia. Haematologica 83: 749, 1998.

4) Hicsonmez G, Suzer K, Suloglu G, Donmez S. Platelet counts in children with iron deficiency anemia. Acta Haematol 60: 85-89, 1978.

5) Vine AK, Samama MM. The role of abnormalities in the anticoagulant and fibrinolytic systems in retinal vascular occlusions. Surv Ophthalmol 37: 283-292, 1993.

6) Kacer B, Hattenbach LO, Horle S, Scharrer I, Kroll P, Koch F. Central retinal vein occlusion and nonarteritic ischemic optic neuropathy in 2 patients with mild iron deficiency anemia. Ophthalmologica 215: 128131, 2001.

7) Kirkham TH, Wrigley PF, Holt JM. Central retinal vein occlusion complicating iron deficiency anaemia. Br J Ophthalmol 55: 777-780, 1971.

8) Imai E, Kunikata H, Udono T, Nakagawa Y, Abe T, Tamai M. Branch retinal artery occlusion: a complication of iron-deficiency anemia in a young adult with a rectal carcinoid. Tohoku J Exp Med 203: 141-144, 2004.

9) Matsuoka Y, Hayasaka S, Yamada K. Incomplete occlusion of central retinal artery in a girl with iron deficiency anemia. Ophthalmologica 210: 358-360, 1996.

10) Saxena VK, Brands C, Crols R, Moens E, Marien P, de Deyn PP. Multiple cerebral infarctions in a young patient with secondary thrombocythemia due to iron deficiency anemia. Acta Neurol (Napoli) 15: 297-302, 1993.

11) Belman AL, Roque CT, Ancona R, Anand AK, Davis RP. Cerebral venous thrombosis in a child with iron deficiency anemia and thrombocytosis. Stroke 21: 488-493, 1990.

12) Aoki N, Sakai T. Cerebral sinus thrombosis in patients with severe iron deficiency anaemia due to myoma uteri. Acta Neurochir (Wien) 97: 131-134, 1989.

13) Malhotra RK, Saraya AK, Kumar R, Choudhry VP, Ghai OP. Platelet aggregation in iron deficiency anemia. Indian J Pediatr 52: 139-145, 1985.

14) Tekin D, Yavuzer S, Tekin M, Akar N, Cin S. Possible effects of antioxidant status on increased platelet aggregation in childhood irondeficiency anemia. Pediatr Int 43: 74-77, 2001.

15) Kabakus N, Yilmaz B, Caliskan U. Investigation of platelet aggregation by impedance and optic methods in children with iron deficiency anaemia. Haematologia (Budap) 30: 107-115, 2000.

16) Caliskan U, Oner AF, Kabakus N, Koc H. Diminished platelet aggregation in patients with iron deficiency anemia. Clin Appl Thromb Hemost 5: 161-163, 1999. 